\title{
Authorship Correction: The Association Between Pain Relief Using Video Games and an Increase in Vagal Tone in Children With Cancer: Analytic Observational Study With a Quasi-Experimental Pre/Posttest Methodology
}

Mario Alonso Puig ${ }^{1}$, MD; Mercedes Alonso-Prieto ${ }^{2}, \mathrm{MD}$; Jordi Miró ${ }^{3}, \mathrm{PhD} ;$ Raquel Torres-Luna ${ }^{2}$, MSN; Diego Plaza López de Sabando ${ }^{4}$, MD; Francisco Reinoso-Barbero ${ }^{2,5}, \mathrm{PhD}$

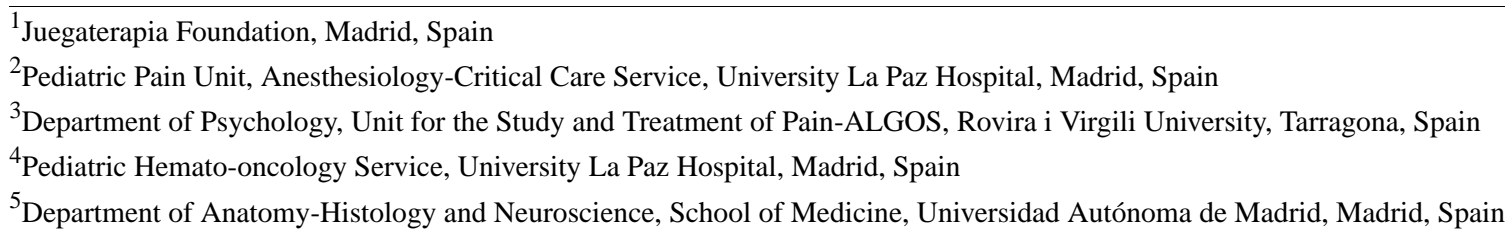

\section{Corresponding Author:}

Mercedes Alonso-Prieto, MD

Pediatric Pain Unit

Anesthesiology-Critical Care Service

University La Paz Hospital

Paseo de la Castellana, 261

Madrid, 28046

Spain

Phone: 34676687569

Email: meme27@hotmail.es

\section{Related Article:}

Correction of: https://www.jmir.org/2020/3/e16013/

(J Med Internet Res 2020;22(7):e19961) doi: 10.2196/19961

In the paper "The Association Between Pain Relief Using Video Games and an Increase in Vagal Tone in Children With Cancer: Analytic Observational Study With a Quasi-Experimental Pre/Posttest Methodology" (J Med Internet Res 2020;22(3):e16013) the authors noticed that one of the authors was not listed on the original published manuscript. The missing author was Mario Alonso Puig; they are first author on the corrected manuscript.

Mario Alonso Puig's affiliation will be listed as "Juegaterapia Foundation, Madrid, Spain" and will appear as affiliation 1 in the corrected manuscript. Author affiliations 1-4 in the original published manuscript will be renumbered to affiliations 2-5 in the corrected manuscript.

The correction will appear in the online version of the paper on the JMIR website on July 7, 2020, together with the publication of this correction notice. Because this was made after submission to PubMed, PubMed Central, and other full-text repositories, the corrected article has also been resubmitted to those repositories.

This is a non-peer-reviewed article. Submitted 17.05.20; accepted 21.05.20; published 07.07.20.

Please cite as:

Alonso Puig M, Alonso-Prieto M, Miró J, Torres-Luna R, Plaza López de Sabando D, Reinoso-Barbero F

Authorship Correction: The Association Between Pain Relief Using Video Games and an Increase in Vagal Tone in Children With

Cancer: Analytic Observational Study With a Quasi-Experimental Pre/Posttest Methodology

J Med Internet Res 2020;22(7):e19961

URL: https://www.jmir.org/2020/7/e19961

doi: $\underline{10.2196 / 19961}$

PMID: 32673254 
CMario Alonso Puig, Mercedes Alonso-Prieto, Jordi Miró, Raquel Torres-Luna, Diego Plaza López de Sabando, Francisco Reinoso-Barbero. Originally published in the Journal of Medical Internet Research (http://www.jmir.org), 07.07.2020. This is an open-access article distributed under the terms of the Creative Commons Attribution License (https://creativecommons.org/licenses/by/4.0/), which permits unrestricted use, distribution, and reproduction in any medium, provided the original work, first published in the Journal of Medical Internet Research, is properly cited. The complete bibliographic information, a link to the original publication on http://www.jmir.org/, as well as this copyright and license information must be included. 